\title{
Genetic Factors Influencing Murine Hematopoietic Productivity in Culture
}

\author{
ROBERT L. PHILLIPS, MATTHEW S. COUZENS, AND GARY VAN ZANT* \\ Department of Anatomy and Cell Biology, University of Michigan Medical School, Ann \\ Arbor, Michigan 48109 (R.L.P., G.V.Z.) and Aastrom Biosciences, Inc., Ann Arbor, \\ Michigan 48106 (M.S.C., G.V.Z.)
}

\begin{abstract}
In order to study a previously described genetic difference manifested in stem cell kinetics of specific mouse strains, effects of this putative gene, $s t k$, were measured on growth and expansion of stem and progenitor cell populations ex vivo. Bone marrow cells from each of two inbred mouse strains, $\mathrm{C} 57 \mathrm{BL} / 6 \mathrm{~J}$ and $\mathrm{DBA} / 2$ ], were placed into separate bioreactor cultures perfused continuously with growth medium containing erythropoietin (Epo), interleukin-3 (IL-3), granulocyte-macrphage colony stimulating factor (GM-CSF), and Kit ligand as well as $5 \% \mathrm{CO}_{2}$. Expansion of cell numbers reached 20-fold for DBA/2] and 10-fold for C57BL/6J marrow within about 1 week of culture. Significant production was also seen of colonyforming unit (CFU)-GM (up nine-fold from input levels) just prior to the cell production peak, and, importantly, moderate expansion of day 12 colony-forming unit-spleen (CFU-S; two- to threefold) occurred as well, although CFU-S production peaked at a relatively short 4 days. CFU-S and CFU-GM levels declined rapidly in culture, either because of unfavorable growth conditions or terminal differentiation. Attempts to remove toxic metabolites by increasing the media perfusion rate resulted in a boost in cell expansion capability by DBA/2) marrow. In bioreactors in which stromal cells were established before marrow inoculation, there was greater expansion of CFU-S (especially by DBA/2J) and CFU-GM, although total cell yield appeared to be unaffected, perhaps because the maximum cell density had already been reached. The relative high potential for CFU-S expansion measured in DBA/2J marrow over that of C57BL/6) will be useful in following genetic contributions to bone marrow production capacity.

(c) 1995 Wiley-Liss, Inc.
\end{abstract}

Hematopoietic stem cells stand at the top of the blood developmental hierarchy and possess the developmental potential to supply at least eight lineages of mature blood cells (Metcalf, 1988). While these cells are thought to be critical for engraftment of myelo-ablated recipients, much more needs to be known about how stem cell self-renewal and differentiation are regulated, both at the molecular and genetic levels. Our purpose in undertaking these studies was to identify stem cell attributes under genetic control and to exploit these to identify and characterize genes responsible for phenotypes significantly affecting their function. The specific phenotype studied in this case was the stem cells' ability to maintain high levels of mature hematopoietic cell output in vitro and to expand populations of primitive cells at the same time.

Many groups have been studying the expansion of primitive hematopoietic progenitor cells in vitro for a number of years. Muench et al. (1993) have used interleukin (IL)-1 and Kit ligand (KL) to expand murine bone marrow in short-term suspension cultures and reported a 200 -fold enrichment in radioprotective ability. Work by Wineman et al. (1993) has shown that the maintenance of the most primitive bone marrow cells (for at least 3 weeks) is dependent upon their interactions with the underlying bone marrow stroma, and that stromal cell lines differ in their abilities to support hematopoiesis. The successful employment of perfusion bioreactor systems for bone marrow by Caldwell et al. (1991) and Palsson et al. (1993) has identified and underappreciated problem in marrow culture; i.e., the buildup of toxic metabolites in the culture media with increasing cell density. Work by Reisbach et al. (1990) showed a positive correlation between IL-3-dependent proliferation and the production of lactic acid in murine hematopoietic cell lines. Blazsek et al. (1991) examined the effects of heliodynamic hormones on bone marrow metabolism and found that the inhibition of lactic acid

Received August 8, 1994; accepted December 2, 1994.

*To whom reprint requests/correspondence should be addressed at Department of Internal Medicine, Markey Cancer Center, University of Kentucky Medical Center, 800 Rose Street, Lexington, KY 40536-0093.

Matthew S. Couzens is now at University of Pennsylvania Medical School, Department of Hematology/Oncology, Philadelphia, PA.

Abbreviations: KL, Kit ligand; GM-CSF, granulocyte-macrophage colony stimulating factor; Epo, erythropoietin; IL-3, interleukin-3; CFU-S/GM, colony-forming unit-spleen or -granulocytemacrophage; BSA, bovine serum albumin; FBS, fetal bovine serum; IMDM, Iscove's modified Dulbecco's medium 
production correlated with terminal differentiation of hematopoietic progenitors. These studies imply that lactic acid buildup may be an unwanted hallmark of high progenitor density. Our presently described studies of in vitro marrow metabolism seem to confirm this hypothesis.

Little study as yet has focused on the genetic contributions to hematopoietic ability either in vitro or in vivo. We previously showed a difference in cell cycling frequency of spleen colony-forming units (CFU-S; very immature progenitor cells) between the two inbred strains of mice studied here, C57BL/6 and DBA/2 (Van Zant et al., 1983). In the DBA $/ 2$ strain, about $20 \%$ of CFU-S were found to be in S-phase of the cell cycle, whereas in $\mathrm{C} 57 \mathrm{BL} / 6$ fewer than $5 \%$ of CFU-S were in cycle. This observation suggested the existence of a gene (or genes), present in only one of the strains, which may control the kinetics of stem cell cycling. The unidentified genetic element was termed stk for stem cell $k$ inetics.

We have further studied this phenotype in C57BL/ $6 \rightarrow \mathrm{DBA} / 2$ allophenic mice (Van Zant et al., 1990). In such aggregated-embryo chimeras, stem cells of both strains are in competition with each other in the same animal. Since the bone marrow stroma was likewise chimeric, possible microenvironmental differences between strains were negated and thus any functional differences were intrinsically regulated. The peripheral blood of these animals was sampled and the relative contribution of stem cells of each strain to the blood cell composition was determined at many time intervals. As these animals aged, the proportion of blood made up of DBA $/ 2$ cells slowly declined, until by 2 years of age no contribution could be seen by $\mathrm{DBA} / 2$ stem cells, and the blood appeared to be $100 \%$ of C57BL/ 6 origin. Interestingly, DBA/ 2 cell production declined at about the natural DBA/2 lifespan (it is the shorter-lived strain of the two). The role of this genetic unit in aging processes is still unclear. However, after transplanting the aged chimeric marrow into an irradiated recipient, DBA/2 cells reappeared in the peripheral blood and actually dominated blood cell output for a short time, after which they again disappeared and were superseded by $\mathrm{C} 57 \mathrm{BL} / 6$ cells. A subsequent marrow transplant into secondary recipients again demonstrated the quiescence, not extinction, of $\mathrm{DBA} / 2$ stem cells. These findings demonstrated an inherent, genetically controlled difference between stem cells of the two strains which was influencing the cells' ability to contribute to blood cell production as well as long-term hematopoietic output.

Recently, we showed that $\mathrm{DBA} / 2 \mathrm{~J}$ mice have a smaller pool of $\mathrm{WGA}^{++} \mathrm{Lin}-\mathrm{Rh}-123^{\mathrm{b}}$ stem cells relative to $\mathrm{C} 57 \mathrm{BL} / 6 \mathrm{~J}$, and that these mice also differ with respect to their recovery times from cytotoxic (5-fluorouracil) injection (Phillips et al., 1992). In addition, we observed that in allophenic mice the DBA/2J component of the blood increased more than that of C57BL/6J when the mice were injected with KL. We are now at a point where we may begin to isolate specific genetic elements which differ between these two strains and which may be responsible for specific phenotypes. In pursuing this work our primary goals were to ascertain whether the $s t k$-controlled genetic differences observed in vivo translate into in vitro cell production, and whether this difference could be used as a phenotypic assay to allow the genetic mapping of the elements involved.

Important to the goal of expanding primitive progenitor cells is an understanding of the physiology of these cells. Early perfusion cultures run by Schwartz et al. (1991) expanded maximally when the medium was perfused continuously at the rate of a half bioreactor volume per day. Work by Palsson et al. (1993), which sought to mimic the in vivo bone marrow environment in vitro, has shown that hematopoietic cell yields and progenitor expansion were dependent upon factors such as seeding density and oxygen concentration. In the present work, we employ a novel perfusion bioreactor system to culture stem cells from these two strains and to analyze their strain-specific hematopoietic growth kinetics in vitro. Through these studies, we have been able to design a working assay for the $s t k$ phenotype which paves the way for genetic and physical mapping.

\section{MATERIALS AND METHODS Animals}

Female C57BL/6J and DBA/2J mice were obtained from The Jackson Laboratory (Bar Harbor, ME) and maintained in a specific pathogen-free facility at the University of Michigan's Unit for Laboratory Animal Medicine according to National Institutes of Health (NIH) guidelines.

\section{Cells}

Bone marrow cell suspensions were obtained by flushing the femora and tibiae with cold Iscove's modified Dulbecco's medium (IMDM; Sigma, St. Louis, MO) containing $10 \%$ fetal bovine serum (FBS). At least three donor mice from each strain were sacrificed for each experiment. Cells were brought to a concentration of $3 \mathrm{million} / \mathrm{ml}$ in Dexter medium (80\% IMDM, 10\% FBS, $10 \%$ horse serum) containing hydrocortisone $(0.1$ $\mathrm{mM}$; Sigma), gentamicin sulfate $(40 \mu \mathrm{g} / \mathrm{ml})$, murine IL-3 (3.75 ng/ml; R\&D Systems, Minneapolis, MN), human erythropoietin (Epo; $0.1 \mathrm{U} / \mathrm{ml}$; Amgen, Thousand Oaks, CA) rat KL (10 ng/ml; Amgen, Thousand Oaks, $\mathrm{CA}$ ), and murine granulocyte-macrophage colony stimulating factor (GM-CSF; $5 \mathrm{ng} / \mathrm{ml}$; R\&D Systems). All growth factors used were from recombinant sources.

\section{Bone marrow perfusion cultures}

Details of these small-scale culture chambers designed for expansion of human bone marrow have been described (Palsson et al., 1993). Whole marrow cells were placed into specially designed bioreactor culture chambers (Aastrom Biosciences, Ann Arbor, MI) at $3 \times 10^{5} \mathrm{cells} / \mathrm{cm}^{2}$ growth area. The cells were incubated overnight at $37^{\circ} \mathrm{C}$ with perfusion of gas but not of growth medium. On the next day, a medium perfusion schedule was begun and continued until the culture was removed for analysis. The medium used was as noted above and was kept at $4^{\circ} \mathrm{C}$ until it was warmed to $37^{\circ} \mathrm{C}$ immediately prior to infusion into the culture vessel. Continuous infusion was maintained by $\mathrm{kdS}$ model 220 syringe pumps (Stoelting, Chicago, IL). Where cultures were perfused at a defined variable rate, a computer was used to adjust the syringe pump infusion rate 
continuously according to the defined schedule. Three groups of cells were then harvested from the reactors: first, the medium (containing nonadherent cells) was aspirated from the reactor with a syringe. Second, the reactors were washed with IMDM and the wash medium was aspirated. Third, the remaining cells were removed with trypsin (Sigma) and subsequent washing with Dexter medium. The three cell fractions thus obtained were denoted as "nonadherent," "loosely adherent," and "adherent," respectively. Cells were counted by hemocytometer and glucose and lactic acid levels were measured on a YSI model 2000 glucose/lactate analyzer (YSI, Yellow Springs, OH).

\section{Stromal establishments}

In cultures in which the stroma was established before inoculation, whole bone marrow cells were isolated from syngeneic strains of mice and irradiated (20.0 Gy) in a Gammacell ${ }^{137} \mathrm{Cs}$ blood irradiator. Three million of these cells were then placed into each bioreactor and the reactors were incubated for 4 days at $33^{\circ} \mathrm{C}$. Dexter medium was completely changed once daily after the second day. On the fifth day, nonadherent cells were removed and discarded and the cultures were inoculated with a fresh suspension of bone marrow cells.

\section{Cell labeling}

Cells were divided into groups and stained with different rat anti-mouse IgG antibodies against lineagespecific antigens: anti-Ly-1 (CD5; T cells, some B cells), anti-Ly-2 (CD8; T-cytotoxic, T-suppressor cells), antiB220 (CD45R; B cells and precursors), anti-Gr-1 (RB68C5; granulocytes), anti-Mac-1 (M1/70.15.11.5; macrophages), and anti-erythroid (TER119; erythrocyte precursors). Lineage-specific antibodies were directly conjugated to fluorescein. Phycoerythrin-conjugated rat anti-mouse $\mathrm{Ly}-6 \mathrm{~A} / \mathrm{E}$ antibody was added to specific samples. All antibodies were obtained from Pharmingen (San Diego, CA) except fluoresceinated anti-Mac-1 (Boehringer Mannheim, Germany), and the TER119 antibody (a gift of Dr. Tatsuo Kina). All incubations were for $20 \mathrm{~min}$ at $4^{\circ} \mathrm{C}$ and washed in IMDM $+0.1 \%$ bovine serum albumin (BSA).

\section{Cell analysis}

Cells were analyzed on an unmodified FACS Vantage instrument (Becton-Dickinson, San Jose, CA). Cells were stained with monoclonal antibodies conjugated directly or indirectly to various fluorochromes, which were excited with either an Ar laser at $488 \mathrm{~nm}$ (for fluorescein or phycoerythrin) or HeNe laser at 633 $\mathrm{nm}$ (for allophycocyanin). The different fluorochromes (allowing for antibody identification) emitted light at different wavelengths (fluorescein at $525 \mathrm{~nm}$, phycoerythrin at $575 \mathrm{~nm}$, allophycocyanin at $675 \mathrm{~nm}$ ) which were detected by sensitive photodetectors placed behind a series of optical filters. At least 10,000 cells were analyzed for each data point. Data analysis was performed using LYSYS II software ( Becton-Dickinson).

\section{Methylcellulose assays}

Cells were plated in methylcellulose medium containing $0.8 \%$ methylcellulose (Methocel; Dow, Midland, MI), 30\% FBS, 1\% BSA, 0.1 mM $\beta$-mercaptoethanol, 40 $\mu \mathrm{g} / \mathrm{ml}$ gentamicin sulfate, $3.75 \mathrm{ng} / \mathrm{ml}$ murine IL-3 (R\&D Systems), $5 \mathrm{ng} / \mathrm{ml}$ murine GM-CSF (R\&D Systems), and $1 \mathrm{U} / \mathrm{ml}$ human Epo (Amgen) in IMDM. All growth factors were from recombinant sources. Cells were incubated for 11 days before counting under a dissecting microscope.

\section{CFU-S assay}

Animals were exposed to total-body irradiation (10.0 Gy in one dose) in a Gammacell-40 irradiator housing dual ${ }^{137} \mathrm{Cs}$ sources. Within $1 \mathrm{hr}$ after irradiation, mice were given a bone marrow transplant containing $1 \%$ of the total cells in pooled bioreactor fractions, so that fractional proportions were maintained. Mice were subsequently housed in a specific pathogen-free facility and sacrificed 12 days later. Spleens were removed and fixed in Carnoy's solution (60\% ethanol, $30 \%$ chloroform, $10 \%$ acetic acid) overnight. Macroscopic spleen colonies were counted the following day.

\section{RESULTS \\ Growth kinetics}

Whole bone marrow was removed from $\mathrm{C} 57 \mathrm{BL} / 6 \mathrm{~J}$ inbred mice and placed into culture in specially designed bioreactors $\left(3 \times 10^{5} \mathrm{cells} / \mathrm{cm}^{2}\right)$. At specific time intervals, cultures were harvested, whereupon cells were counted and lactic acid levels were measured in the efflux medium. As shown in Figure 1A, the cell number first declined by about $33 \%$ from the original 3 million cells, then began to rise rapidly during days 2-6. After day 6 , the cell production slowed considerably, and total cell number began to decline after about day 8 . Human marrow in these bioreactor cultures, by comparison, reaches a cell plateau at about day 14 (Koller et al., 1993). This difference in growth kinetics may be linked to differences in cell cycling rates between mice and humans.

Each time reactors were harvested, cells were plated in methylcellulose medium containing Epo, IL-3, and GM-CSF and day 11 colonies were counted. As shown in Figure 1B, CFU-GM levels rose markedly but transiently, reaching a peak just prior to the total cell peak. This was anticipated since CFU-GM would be expected to give rise to many mature cells in the presence of high growth factor concentrations in these cultures.

At various times, harvested cells were stained with antibodies against specific mature cell lineage antigens (macrophages, Mac-1; granulocytes, Gr-1, erythrocytes and progenitors, TER119; T cells, CD5; B cells, CD45R; T-cytotoxic cells, CD8), as well as the hematopoietic stem cell antigen Sca-1 (Ly-6A/E). Three trends emerged from these studies: the expansion of myeloid cells, the decline of lymphoid and erythroid cells, and the relative stability of progenitors recognized by the Sca-1 antibody. As depicted in Figure 2, numbers of myeloid cells co-expressing Gr-1 and Mac-1 antigens rose considerably during the first few days of culture, while lymphoid (CD5, CD8, CD45R) and erythroid (TER119) cells declined to insignificant levels. Cells positive for Sca-1 remained in about the same proportion throughout culture, indicating that perhaps Sca- $1^{+}$cells expand at about the same rate as the whole culture. 

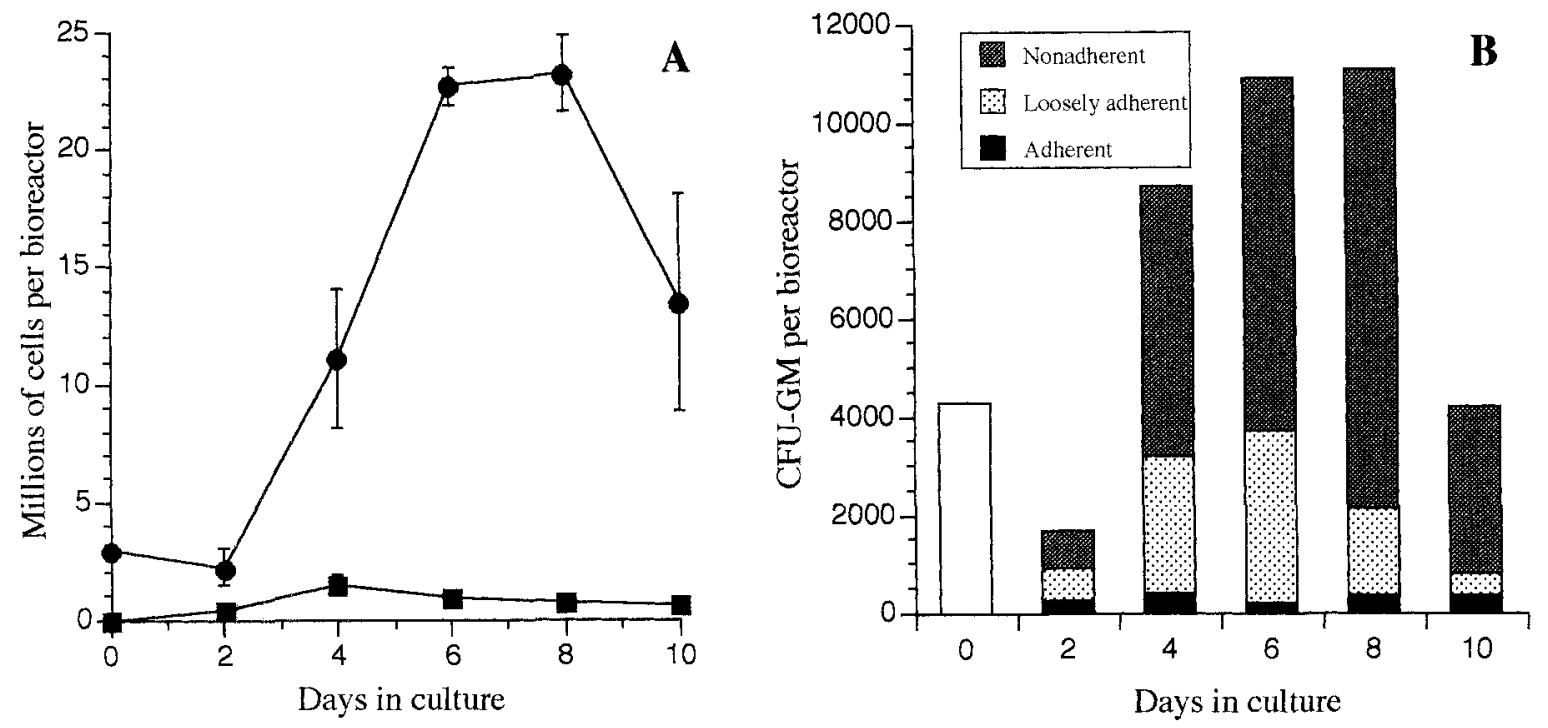

Fig. 1. A: Bone marrow growth kinetics of $\mathrm{C} 57 \mathrm{BL} / 6 \mathrm{~J}$ cultures in perfusion bioreactors. $\bullet$ nonadherent cells; $\square$, adherent cells. Three million whole marrow cells were inoculated into the bioreactors on day 0 and media perfusion was begun a day later. B: Expansion of CFU-GM in C57BL/6J bone marrow cultures. The three cell fractions

were obtained from the bioreactor vessels as described. At least three separate cultures contributed to each data point. Data shown are representative of three separate experiments, each performed in triplicate.

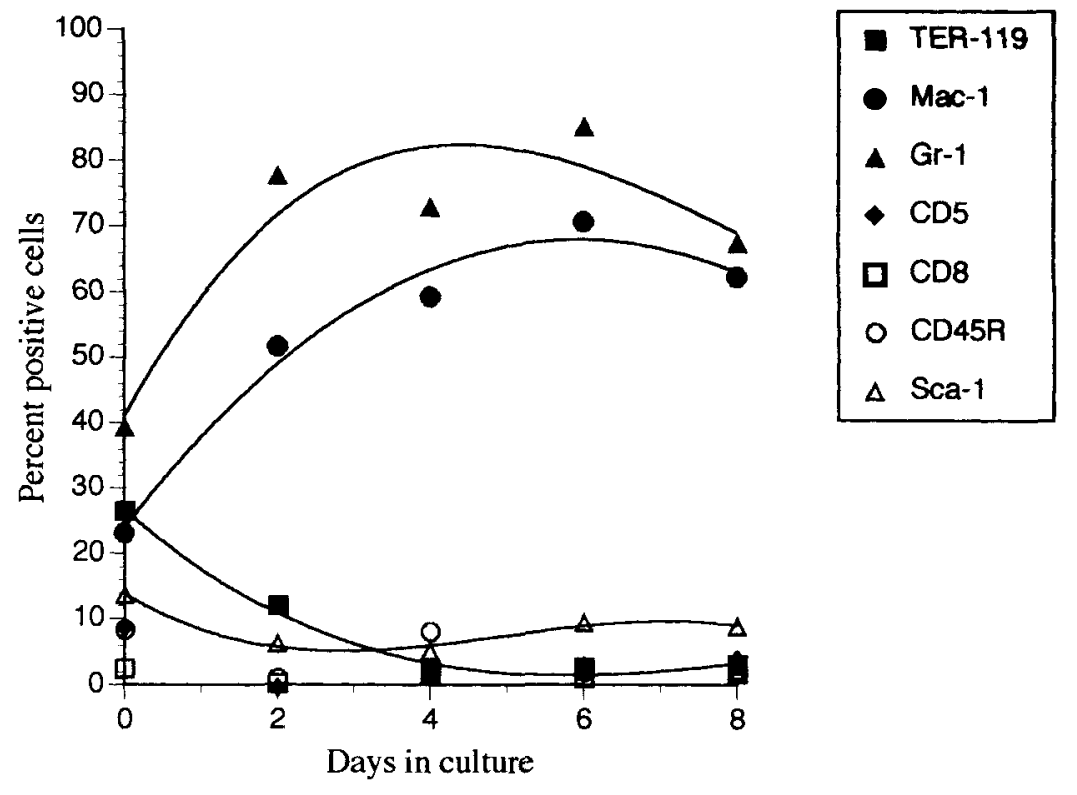

Fig. 2. Expression of various cell surface antigens on the cultured marrow cells. Note that levels of Gr-1 and Mac-1 positive cells are greatly increased, and that many cells appear to be Gr-1-Mac-1 double positive. Note that TER119 (erythroid) cells disappear in culture. Three separate cultures were used to provide cells for the measurements; at least 10,000 cells were analyzed for each data point.

\section{Numbers of primitive CFU-S rise transiently in culture}

At various times, $1 \%$ of total harvested cells were injected into lethally irradiated $(10.0 \mathrm{~Gy})$ recipient mice. Figure 3 shows the CFU-S per reactor for both C57BL/6J and DBA/2J strains at several time points. While moderate expansion of CFU-S was seen early on (more than twofold), little CFU-S activity was found in longer-term cultures. Whether this decline is the result of progenitor cell death caused by suboptimal growth conditions or simply differentiation remains to be determined, but the large number of CFU-GM produced may indicate that the vast stem cell potential for differentiation may be able to accommodate the CFU-GM 


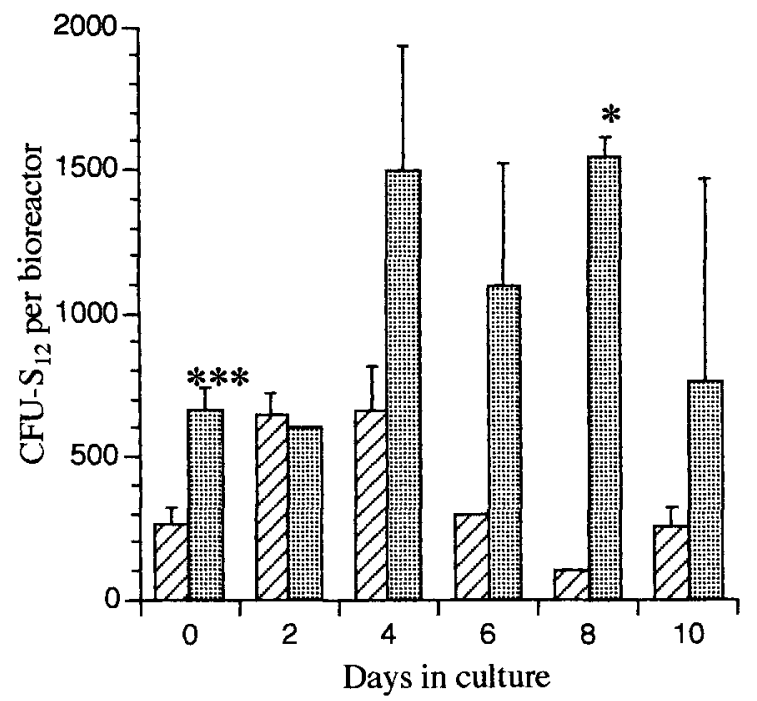

Fig. 3. CFU-S expansion in bioreactor cultures. Hatched bars, C57BL/6J; shaded bars, DBA/2J. CFU-S appeared to rise transiently by about fourfold, then disappear in later cultures. Note the greater magnitude and duration of CFU-S expansion by DBA/2J marrow. Asterisks denote statistically significant higher levels of CFU-S in DBA/ $2 \mathrm{~J}$ cultures at day 0 (Student's t test; ${ }^{* * * P}<0.001$ ) and day 8 $(* P<0.05)$. At least three cultures assayed in at least five mice were used for each data point.

expansion seen here with ease. Note that both the magnitude and duration of CFU-S production were higher in the DBA/2J cultures, relating back to the original studies on CFU-S cycling in these two strains (Van Zant et al., 1983).

\section{A rise in lactic acid levels correlates with a slowdown in cell growth}

After about day 4 of culture, lactic acid levels in the efflux medium began to increase sharply, coinciding with the beginning of the period of the most rapid cell expansion (Fig. 4). There was also a corresponding sharp drop in glucose concentration, indicating that glucose was being metabolized anaerobically to lactic acid. When lactate levels rose above an apparent critical level of $10 \mathrm{mmol} / \mathrm{L}$ in the efflux medium, cell expansion slowed and cell number soon declined, suggesting that lactic acid levels may limit cell expansion in vitro. It should be noted that lactate levels were measured in bioreactor effluent, and may be much higher in proximity to the cell bed. Interestingly, when the molar changes in glucose and lactate were compared, it was found that the molar ratio of glucose consumed to lactate produced (influx vs. efflux media) was l:1.9; nearly the 1:2 theoretical ratio for complete anaerobic metabolism. Why these cells appear to undego anaerobic metabolism is a mystery, but since the ratio never reached $1: 2$, it is thought that a subset of the marrow cells (e.g., the stroma) may be utilizing molecular oxygen, while the myeloid cells (comprising the vast majority of total cells) are not (Caldwell et al., 1991).

In order to test whether oxygen was actually being used by the cultures, experiments were run in which some cultures' gas lines contained $40 \% \mathrm{O}_{2}$ (and $5 \% \mathrm{CO}_{2}$,

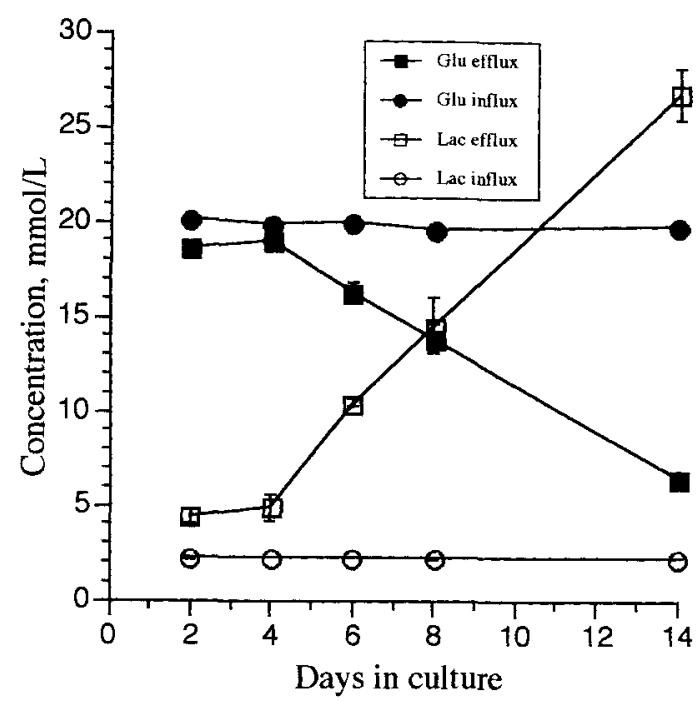

Fig. 4. Levels of glucose and lactate in $\mathrm{C} 57 \mathrm{BL} / 6 \mathrm{~J}$ bioreactor cultures. Circles, influx medium levels; squares, efflux medium levels; open symbols, lactate; closed symbols, glucose. Despite the perfusion of growth medium, lactate levels began to rise along with cell number and eventually halted growth of the culture. Note that the molar ratio of glucose consumed to lactate produced is nearly $1: 2$, indicating that the vast majority of these cells are utilizing glucose anaerobically, despite the perfusion of air through the cultures. Three cultures were analyzed three times (total of nine measurements) for each data point; error bars represent the standard deviation of the combined data. Data presented are representative of the results obtained in three individual experiments.

TABLE 1. Effect of different oxygen concentrations on cell expansion ${ }^{1}$

\begin{tabular}{lcc}
\hline & \multicolumn{2}{c}{ Millions of cells } \\
\cline { 2 - 3 } Percent oxygen & Adherent & Nonadherent \\
\hline Sealed) & $1.3 \pm 1.4$ & $27.3 \pm 5.4$ \\
20 & $1.4 \pm 0.4$ & $30.7 \pm 3.8$ \\
40 & $1.6 \pm 0.4$ & $32.6 \pm 5.2$
\end{tabular}

${ }^{1}$ Oxygen concentration in the perfused gas does not seem to affect the total cell yield of these cultures, possibly because the cell number is already at its maximum dictated by lactic acid levels. The increased oxygen tension did not affect levels of glucose and lactate in these cultures (data not shown). The following growth factors were added to each milliliter of culture medium: IL-3 (5 ng), GM-CSF ( $5 \mathrm{ng}$ ), Epo (0.1 U), and KL (10 ng). Cultures were harvested at 8 days.

balance: nitrogen), while others contained incubator air $\left(21 \% \mathrm{O}_{2}+5 \% \mathrm{CO}_{2}\right)$. In addition, some cultures were run with the gas lines sealed, so that the only oxygen available was that in the chamber originally, plus the small amount dissolved in the warm medium. The cell yields of these three groups at day 6 of culture are depicited in Table 1 . While there appeared to be no significant detrimental effect of oxygen starvation on the cultures, they likewise showed no evidence of oxygen toxicity at $40 \% \mathrm{O}_{2}$ and cell numbers may have even been increased slightly. Lactic acid production and glucose consumption were not significantly different among the three groups, supporting the idea that glucose was being metabolized anaerobically. Unexpectedly, there were differences in progenitor numbers (Fig. 5). With perfusion of $40 \% \mathrm{O}_{2}$, there was a $41 \%$ increase in numbers of CFU-GM, possibly because of metabolically favorable conditions for the stromal cells, 


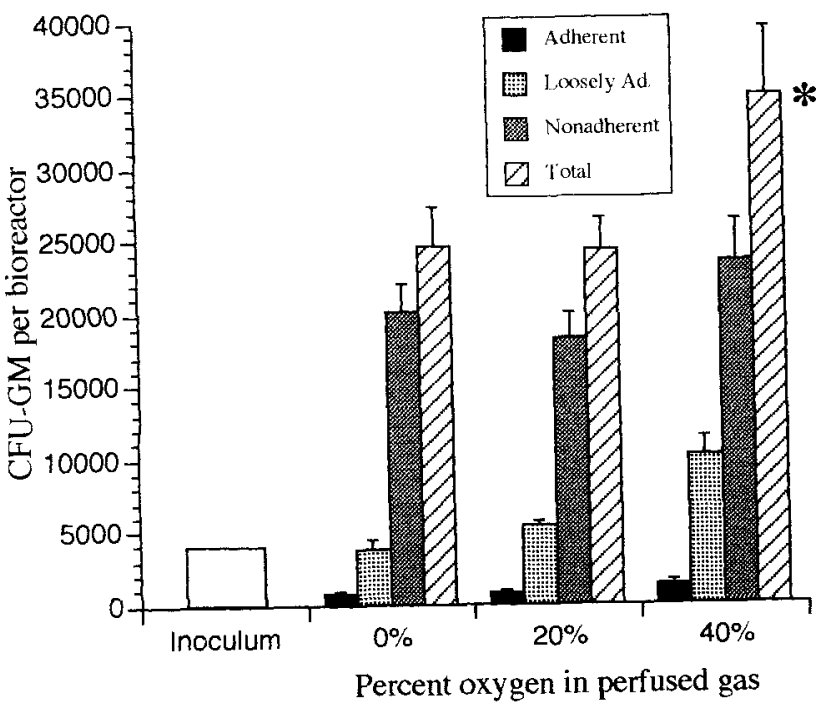

Fig. 5. Day 6 CFU-GM expansion in strain C57BL/6J at different oxygen tensions. Increased levels of oxygen in the perfused gas have a positive effect on CFU-GM colony expansion in all fractions. The asterisk denotes that the total colony numbers at $40 \%$ oxygen were significantly greater (Student's t test; $P<0.05$ ) than those of either the $0 \%$ or the $20 \%$ groups. Three separate cultures were used in each group.

which in turn had an impact on the hematopoietic cells close to them (the loosely adherent population). These data argue that molecular oxygen was indeed being consumed by the cultures, and that possibly an energy source other than glucose was being metabolized aerobically.

\section{Marrow cultured with a variable perfusion rate shows strain-specific growth kinetics}

In an effort to minimize the adverse effect of waste products such as lactate on cell growth, the media perfusion rate was increased smoothly (by computer) on a linear scale from 0.18 to 1.8 reactor volumes/day over the course of 1 week, so that the perfusion rate increased somewhat proportionally with cell number. Surprisingly, C57BL/6J marrow showed a minimal increase in hematopoietic output under the variable rate schedule, while output by DBA/2J marrow cultured under identical conditions almost doubled, so that the total expansion of cells in DBA/2J cultures was almost 20 -fold by the 8 th day of culture (Fig. 6). Additionally, the duration of cell growth in both cultures was extended. The slowing of the growth rate at about the 8th day was accompanied again by rising lactate levels (lactate in the efflux media at day 8 was above $10 \mathrm{mmol} / \mathrm{L}$, suggesting a limiting effect that lactic acid has on bone marrow expansion in vitro.

\section{Stromal cell growth correlates with higher progenitor concentrations}

Since the establishment of the stromal (adherent) layer in culture tended to mark the beginning of the burst of hematopoietic output, we attempted to induce a higher output rate by establishing stroma before inoculation of the cultures with whole bone marrow. Four

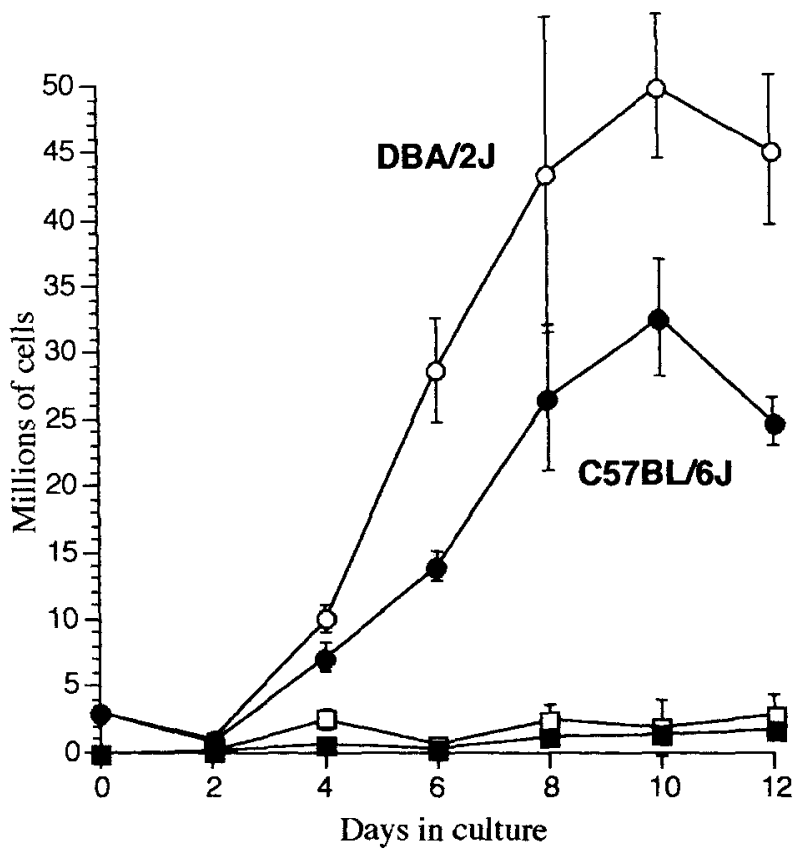

Fig. 6. Total nonadherent cell yield in variable-rate perfusion cultures of $\mathrm{C} 57 \mathrm{BL} / 6 \mathrm{~J}(\bullet)$ vs. DBA $/ 2 J(0)$. Adherent cells are denoted by for C57BL/6J and $\square$ for DBA/2J. DBA/2J cells outexpanded C57BL/6J two to one when the medium perfusion was increased to respond to the demands of cell mass. The medium perfusion rate was controlled by computer and followed a linear schedule, so that the rate had increased by 10 -fold over the course of 1 week of culture. After the first week, the rate was held constant at $8 \mathrm{~mL} /$ day (bioreactor volume is 4.5 $\mathrm{mL}$ ). At least three separate cultures contributed to each data point.

days before inoculation, bioreactors were "seeded" with irradiated $(20 \mathrm{~Gy})$ whole syngeneic marrow. At the time of inoculation, the nonadherent and loosely adherent fractions were removed, leaving a sparse monolayer of stromal cells. Whole syngeneic marrow was introduced onto this monolayer and expanded under the linear rate schedule specified above for various lengths of time.

Figure 7A shows the total cell yield of C57BL/6J and DBA/2J marrow in such cultures. While the presence of preformed stromal cells did not appear to affect the total cell yield of the cultures significantly, there was a positive effect on CFU-S support (Fig.7B) After 8 days on preformed stroma, CFU-S levels in DBA-2J cultures were about threefold higher than in the DBA/2J inoculum, and about fivefold higher than in the corresponding $\mathrm{C} 57 \mathrm{BL} / 6 \mathrm{~J}$ culture. Given our earlier data on relative cycling rates of CFU-S between C57BL/6J and DBA/2J, this observation may lead to the development of a phenotypic assay for the effects of the $s t k$ gene.

\section{DISCUSSION}

Perfusion bioreactors were employed to culture whole bone marrow for 1-2 weeks and to identify the specific in vitro growth requirements of bone marrow cells in general and of hematopoietic stem cells in particular. Using this novel system for culturing bone marrow, we demonstrate expansion of total marrow cells by 10- to 20 -fold in 1 week, and increases in CFU-GM by about ninefold over levels in the inoculum. Moreover, 


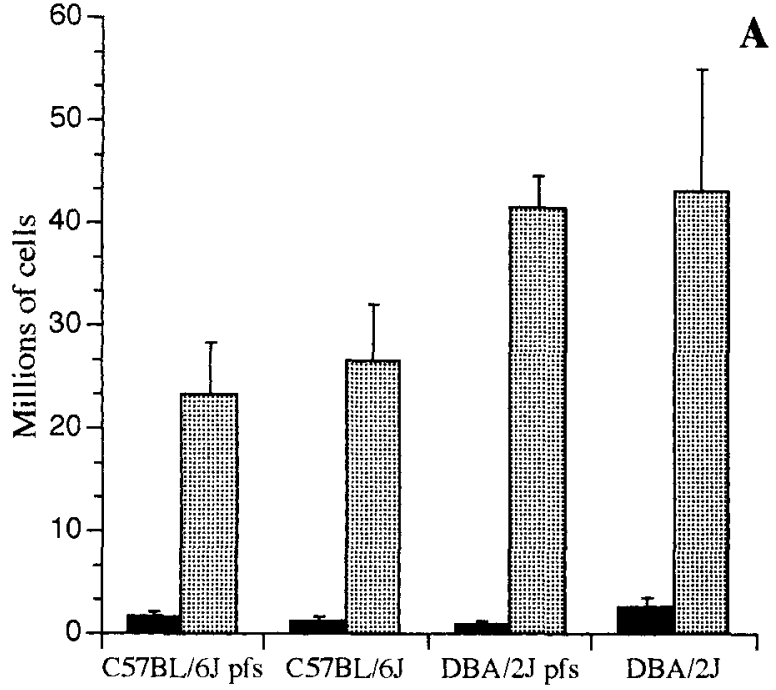

Fig. 7. A: Cell yields at day 8 of cultures grown on preformed syngeneic stroma. Black bars, adherent cells; shaded bars, nonadherent cells. Total cell yield did not differ significantly from those of control (nonpreformed stroma) cultures, possibly because the cell number had been limited by rising lactic acid levels. B: Expansion of CFU-S on preformed syngeneic stroma. Twelve-day CFU-S levels expanded in both cultures at day 8 , but DBA/2J showed higher absolute CFU-S

the day 12 CFU-S population was found to expand by as much as threefold using this culture system.

Compared with human bone marrow cultured in these bioreactors, our murine cultures show faster growth kinetics. Maximum cell density of about 3 million $/ \mathrm{m}^{2}$ (for $\mathrm{C} 57 \mathrm{BL} / 6 \mathrm{~J} ; 6$ million for $\mathrm{DBA} / 2 \mathrm{~J}$ ) was reached in about 7 days (Fig. 1A), whereas in human cultures, maximum density (roughly $3 \mathrm{million} / \mathrm{m}^{2}$ ) takes twice as long (Koller et al., 1993). The growth kinetics of bone marrow cells are a complex function of many different cell types (and thus, growth requirements) and culture conditions that are always in flux. Within 2 days of culture, we saw a general decline in cell number to about $30-60 \%$ of the inoculum, perhaps because apoptosis of specific cells was taking place due to a lack of uncharacterized essential growth factors (Koury, 1992; Williams et al., 1990; Yu et al., 1993), and because of the very limited lifespan of mature granulocytes prevalent in the inoculum. This possibility was corroborated by flow cytometric evidence showing that a decline in cells bearing lymphoid and erythroid (despite the presence of Epo) surface antigens occurs very shortly after the beginning of culture (Fig. 2). Similar to observations in human cultures by Meagher et al. (1988) and Schwartz et al. (1991), levels of Gr-1 and Mac-1 positive cells increased greatly, dominating the bioreactor output by 4 days of culture. This accumulation may be a direct effect of the presence of GM-CSF in the perfused medium, suggesting that culture conditions may be altered to generate desired cell compositions (Cormier et al., 1991; Dexter et al., 1990). A corresponding massive increase in CFU-GM numbers was also seen just prior to the peak in total cell numbers (Fig. 1B).

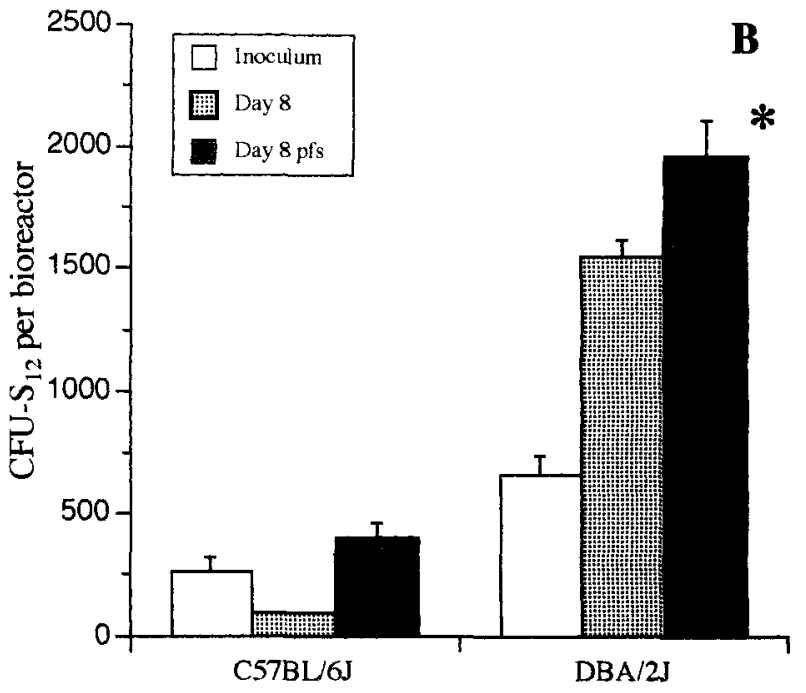

levels as well as a higher (threefold) expansion rate. The asterisk denotes that CFU-S expansion (for DBA/2J cultures) was significantly greater (Student's t test; $P<0.05$ ) in the preformed stroma group than in cultures without preformed stroma or when compared to the inoculum. At least three cultures were used for each data point; three mice were used for each CFU-S assay.

In order to investigate the dynamics of more primitive cells, we periodically injected $1 \%$ of the total reactor cells into lethally irradiated syngeneic mice to measure CFU-S $\mathrm{S}_{12}$ levels. We found definite expansion of CFU-S early in the culture, but these cells appeared either to senesce or become deeply quiescent in older cultures. It is possible that a sufficient concentration of potent growth factors was present in the culture medium such that the CFU-S were stimulated to differentiate and were "used up." Of equal likelihood is the possibility that a maximum concentration of hematopoietic cells had been generated in these small cultures, and the buildup of toxic metabolites or other inhibitory factors had caused the CFU-S (and more primitive cells) to enter a deep cell cycle quiescence $\left(\mathrm{G}_{0}\right.$ phase) or maybe even killed them altogether. The fact that CFU-S did not appear in late-stage cultures means that they were unable to generate colonies when placed into an irradiated recipient animal in a bone marrow transplant; this implies that they were unable to reactivate and may be either dead or terminally differentiated.

Bone marrow cultures tended to decline after about a week, and we investigated the corrigible limitations of long-term growth. Since lactic acid levels began to mount as the culture reached its growth peak, we attempted to reduce and remove lactic acid a) by adjusting the availability of molecular oxygen to the cell bed and $b$ ) by increasing the media perfusion rate to carry away such waste products. When the concentration of oxygen in the perfused gas was increased to $40 \%$, the cultures showed no real increase in total cell yield (Table 1). Interestingly, none of the three groups of cultures (nonperfused, air only, or double oxygen concen- 
tration) differed significantly in terms of cell yield, indicating that a) we found no evidence of oxygen toxicity in these cultures even at $40 \%$ oxygen, and b) the vast majority of these cells appear not to need oxygen perfusion, perhaps linked to the discovery that most of them are metabolizing glucose anaerobically. Another explanation for similar cell yields among the three groups may lie in the metabolic studies: glucose and lactate levels remained similar for the three groups as well, and it follows that buildup of lactic acid was inhibiting further growth, so that the maximum culture size had been reached. In order to rule out glucose deprivation as a reason for culture decline, we set up one group of cultures with $25 \mathrm{mM}$ glucose in the medium (instead of the normal $20 \mathrm{mM}$ ) and found that while glucose levels remained relatively higher, lactate production and culture longevity remained unaffected (data not shown). In oxygen-excess experiments, we were unsuccessful in our attempts to change the glucose:lactate molar ratio from approximately $1: 1.9$, indicating that these cultures were receiving enough molecular oxygen to fit specific needs of the cells. When we measured CFU-GM levels among these groups, we found that higher oxygen concentrations resulted in higher CFU-GM output, in disagreement with data from cultured human marrow (Koller et al., 1992). Whether the CFU-GM population uses molecular oxygen or whether the supporting (stromal) cells are induced into a higheroutput state by oxygen availability is unknown. Increasing the perfusion rate resulted in significant gains in cell yield, but total glucose usage and lactic acid production remained unchanged, suggesting that mounting lactic acid levels may be a major cause of the decline of long-term cultures. In observing human bone marrow cultures, Meagher et al. (1988) have shown evidence that reactive oxygen intermediates generated by the accumulation of myeloid cells may also play a role in limiting progenitor expansion.

In cultures in which a variable media perfusion rate was used, DBA/2J output exceeded by nearly twofold that of $\mathrm{C} 57 \mathrm{BL} / 6 \mathrm{~J}$ in parallel cultures. Since the same conditions were used for marrow culture in the two groups, our only conclusion can be that this difference arises from an uncharacterized inherent difference between bone marrow cells of these two strains. Likewise, CFU-GM and CFU-S expansion rates were different between these groups: DBA/2J cultures consistently showed higher expansion rates of all cells measured. Given that previous data have shown a higher steady. state rate of CFU-S cycling in the DBA/2J strain, it is of interest to note that the day 0 (steady-state in vivo) CFU-S levels were approximately twofold higher in $\mathrm{DBA} / 2 \mathrm{~J}$ animals than in C57BL/6J (Table 2). Whether this observation by itself may account for all of the $\mathrm{DBA} / 2 \mathrm{~J}$ productivity advantages seen in culture is unknown, but CFU-S expansion in DBA/2J cultures over that of $\mathrm{C} 57 \mathrm{BL} / 6 \mathrm{~J}$ was greater (at later time points) than the twofold increase that might be expected from the steady-state CFU-S differences depicted in Table 1. While the steady-state CFU-S difference between these two strains may be only partially related to differences in hematopoietic output, this observation will nevetheless become helpful in mapping the trait with recombinant inbred strains. The observation that $\mathrm{DBA} / 2 \mathrm{~J}$ he-
TABLE 2. Steady state in vivo levels of CFU-S in C57BL/6J and DBA/2J strains ${ }^{1}$

\begin{tabular}{|c|c|c|}
\hline Strain & $\mathrm{n}$ & Colonies $/ 10^{5}$ cells \\
\hline $\mathrm{DBA} / 2 \mathrm{~J}$ & 22 & $19.4 \pm 3.3$ \\
\hline $\mathrm{C} 57 \mathrm{BL} / 6 \mathrm{~J}$ & 10 & $9.8 \pm 2.6$ \\
\hline Ratio & & \\
\hline
\end{tabular}

${ }^{1}$ Mice were given a lethal dose of radiation (10.0 Gy) followed by a bone marrow transplant of $5 \times 10^{4}$ fresh marrow cells intravenously. Living mice were sacrificed 12 days later and spleens were removed and fixed in Carnoy's solution overnight. Macroscopic colonies were enumerated the next day.

matopoietic output was greatly increased over that of $\mathrm{C} 57 \mathrm{BL} / 6 \mathrm{~J}$ in these cultures is in agreement with our earlier in vivo data from allophenic mice (Van Zant et al., 1990; Phillips et al., 1992) indicating that DBA/2J marrow, because of some inherent kinetic advantage, dominates competitive hematopoiesis in vivo and responds faster to in vivo growth factor stimulation. If, as has been hypothesized, DBA/2J stem cells have a higher baseline rate of stem cell cycling, it seems logical that there might be more CFU-S in the marrow to ensure that stem cell populations are never depleted in vivo. Though there may be little direct correlation between total output and CFU-S cycling in these cultures, we have found differences in CFU-S expansion in culture (Fig. 7) which may reflect the original observations (Van Zant et al., 1983).

When a stromal monolayer was allowed to grow before marrow introduction, no real increase in cell yield was seen, possibly because the sizes of these culture are already being limited by lactate levels in later stages, but day 12 CFU-S numbers were significantly higher (Fig. 7). The fact that cultures grown on preformed stroma behaved differently from control cultures underscores the importance of stromal-stem cell intereactions in hematopoiesis. It has been shown that the bone marrow stroma is necessary for productivity of murine (Dexter et al., 1976; Wineman et al., 1993) as well as human cultures (Koller et al., 1993), and we have evidence supporting earlier observations (Quesenberry et al., 1987) that the stromal microenvironment has a real effect on hematopoietic output in this system. It seems likely that the stromal remains a complex source of undiscovered cytokines or other factors acting at once positively and negatively on stem cells to give the entire hematopoietic system its considerable dynamic range (Daniel et al., 1989). Established stromal cell lines have been found to differ significantly in levels of hematopoietic support (Wineman et al., 1993), and we are investigating the use of these in optimizing the expansion of stem cells from fresh bone marrow.

The characterization of the genetic elements involved in this differential bone marrow growth will be helpful in bone marrow transplantation and in gene therapy. Probes of patient cells for the human stk homologue may be used to evaluate transplant prognosis or to indicate what sorts of adjunct therapy may be required to ensure transplant success in "slow kinetics" patients. The introduction of a "fast kinetics" gene into hematopoietic cells to be used in gene therapies may provide the level of competitiveness necessary so that the therapeutic gene is expressed by a sufficient number of cells. Our finding that CFU-S numbers increased 
in $\mathrm{DBA} / 2 \mathrm{~J}$ cultures at a greater rate and to greater numbers than corresponding $\mathrm{C} 57 \mathrm{BL} / 6 \mathrm{~J}$ cultures indicates that the original observations of stk phenotype in vivo do indeed apply to in vitro hematopoiesis. Furthermore, the results described herein allow for the design of a working in vitro assay for the stk phenotype, so that analysis of recombinant inbred (BXD) strains of mice and other fine genetic and physical mapping strategies may be undertaken. It is our objective to clone the genes involved in this phenotype and to identify the human $s t k$ homologues.

\section{ACKNOWLEDGEMENTS}

We thank Dr. Tatsuo Kina (Kyoto University, Kyoto, Japan) for the kind gift of TER119 antibody and Drs. Krisztina Zsebo and Joan Egrie of Amgen for the gifts of recombinant rat KL and recombinant human Epo, respectively. We also thank Drs. Bernhard Palsson, Christa Muller-Sieburg, and Robert Herforth for helpful discussions, and we are grateful to Jeff Boesiger and Brian Newsom for expert technical assistance, as well as to the staffs of the University of Michigan's Hospital Blood Bank and Unit for Lab Animal Medicine. This work was supported by National Institutes of Health grant R01 CA40575 and Aastrom Biosciences, Inc.

\section{LITERATURE CITED}

Blazsek, I., Comisso, M., Farabos, C., and Misset, J.L. (1991) Roles for the heliodynamic hormones all-trans retinoic acid and 1-alpha, 25dihydroxyvitamin D3 in control of the hematopoietic cell cycle. Biomed. Pharmacother., 45:157-168.

Caldwell, J., Palsson, B.O., Locey, B., and Emerson, S.G. (1991) Culture perfusion schedules influence the metabolic activity and granulocyte-macrophage colony stimulating factor production rates of human bone marrow stromal cells. J. Cell. Physiol., 147:344-353.

Cormier, F. Ponting, I.L., Heyworth, C.M., and Dexter, T.M. (1991)

Serum-free culture of enriched murine hematopoietic stem cells $I$ : Effect of hematopoietic growth factors on proliferation. Growth Factors, 4:157-164.

Daniel, C.P., Ponting, I.L., and Dexter, T.M. (1989) Growth and development of haemopoietic cells: A deterministic process? Hematol. Bluttransfus., 32:172-177.

Dexter, T.M., Allen, T.D., and Lajtha, L.G. (1976) Conditions controlling the proliferation of hematopoietic stem cells in vitro. J. Cell. Physiol., 91:335-344.

Dexter, T.M., Heyworth, C.M., Spooncer, E., and Ponting, I.L. (1990) The role of growth factors in self-renewal and differentiation of haemopoietic stem cells. Philos. Trans. R. Soc. Lond. [Biol.], 327:8598.
Koller, M.R., Bender, J.G., Miller, W.M., and Papoutsakis, E.T. (1992) Reduced oxygen tension increases hematopoiesis in long-term culture of human stem and progenitor cells from cord blood and bone marrow. Exp. Hematol, 20:264-270.

Koller, M.R. Emerson, S.G., and Palsson, B.O. (1993) Large-scale expansion of human stem and progenitor cells from bone marrow mononuclear cells in continouous perfusion cultures. Blood 82:378384

Koury, M.J. (1992) Programmed cell death (apoptosis) in hematoipoiesis. Exp. Hematol., 20:391.

Meagher, R.C. Salvado, A.J., and Wright, D.G. (1988) An analysis of the multilineage production of human hematopoietic progenitors in long-term bone marrow culture: Evidence that reactive oxygen intermediates derived from mature phagocytic cells have a role in limiting progenitor cell self-renewal. Blood, 72:273-281.

Metcalf, D. (1988) The Molecular Control of Blood Cells. Harvard Univ. Press, Cambridge, MA, pp. 1-18.

Muench, M.O., Firpo, M.T., and Moore, M.A. (1993) Bone marrow transplantation with interleukin-1 plus $K$ it ligand ex vivo expanded bone marrow accelerates hematopoietic reconstitution in mice without the loss of stem cell lineage and proliferative potential. Blood, $81: 3463-3473$

Palsson, B.O., Paek, S.-H., Schwartz, R.M., Palsson, M., Lee, G.-M., Silver, S., and Emerson, S.G. (1993) Expansion of human bone marrow progenitor cells in a high cell density continuous perfusion system. Biotechnology, 11:368 372

Phillips, R.L., Reinhart, A.J., and Van Zant, G. (1992) Genetic control of murine hematopoietic stem cell pool sizes and cycling kinetics. Proc. Natl. Acad. Sci. USA, 89:11607-11611.

Quesenberry, P.J., McNiece, I.K., Robinson, B.E., Woodward, T.A. Baber, G.B., McGrath, H.E., and Isakson, P.C. (1987) Stromal cell regulation of lymphoid and myeloid differentiation. Blood Cells, 13:137-146.

Reisbach, G., Ellwart, J., and Dormer, P. (1990) Lactate production and amino acid incorportation in interleukin-3-dependent, factordeprived hemopoietic murine cell lines. Exp. Cell Res., 190:175178 .

Schwartz, R.M., Palsson, B.O., and Emerson, S.G. (1991) Rapid media perfusion rate significantly increases productivity and longevity of human bone marrow cultures. Proc. Natl. Acac. Sci. USA, 88:67606764

Van Zant, G., Eldridge, P.W., Behringer, R.R., and Dewey, M.J. (1983) Genetic control of hematopoietic kinetics revealed by analyses of allophenic mice and stem cell suicide. Cell, 35:639-645.

Van Zant, G., Holland, B.P., Eldridge, P. W., and Chen, J.-J. (1990) Genotype-restricted growth and aging patterns in hematopoietic stem cell populations of allophenic mice. J.Exp. Med., 171:15471565 .

Williams, G.T., Smith, C.A., Spooncer, E., and Dexter, T.M. (1990) Haemopoietic colony-stimulating factors promote cell survival by suppressing apoptosis. Nature, 343:76-78.

Wineman, J.P. Nishikawa, S., and Muller-Sieburg, C.E. (1993) Maintenance of high levels of pluripotent hematopoietic stem cells in vitro: Effect of stromal cells and c-kit. Blood, 81:365-372.

Yu, H., Bauer, B., Lipke, G.K., Phillips, R.L., and Van Zant, G. (1993) Apoptosis and hematopoiesis in murine fetal liver. Exp. Hematol., $81: 373-384$. 